\title{
EFFECT OF THE GLONASS-SPECIFIC RECEIVER ANTENNA PHASE CENTER CORRECTIONS ON THE RESULTS OF EUROPEAN REGIONAL GNSS NETWORK
}

\author{
Tomasz Liwosz \\ Department of Geodesy and Geodetic Astronomy \\ Warsaw University of Technology, Poland \\ email: tomasz.liwosz@gik.pw.edu.pl
}

\begin{abstract}
In the paper I investigated the effect of the GLONASS-specific receiver antenna phase center corrections on the results of a regional permanent GNSS network. I made analysis, using Bernese GPS Software 5.0, of GPS-only and GPS-GLONASS (GNSS) observations collected at permanent sites in Europe. Two types of GNSS solutions were computed: with GPS phase center corrections used for observations of both systems, and with the system specific corrections for observations of the respective system. The Bernese software was modified accordingly to use GLONASS specific corrections for GLONASS measurements. The results, i.e., coordinates and tropospheric zenith delays were analyzed and compared between computed solutions. Introducing GLONASS-specific receiver antenna phase center corrections did not improve the repeatability of the GNSS coordinate time series. Differences of coordinates between the two GNSS solutions were highly repeatable but offsets (biases) were observed; maximum bias for horizontal component was $1 \mathrm{~mm}$ and $4 \mathrm{~mm}$ for up component. Similar biases were observed for stations with the same antenna models. Periodic signal with a period of $1 / 3$-year was found in difference time series between GPS and GNSS solutions for north component with a maximum peak-to-peak amplitude $2.8 \mathrm{~mm}$. The periodic signal was attributed to GLONASS.
\end{abstract}

Keywords: GNSS analysis, GLONASS, GNSS receiver antenna, phase center correction

\section{INTRODUCTION}

The constellation of the Global Navigation Satellite System (GLONASS) has recently greatly improved; since November 2011 there are 24 operational GLONASS satellites. The full constellation, i.e., 24 operational satellites in space, has been reached by GLONASS for the second time in history. In 1996 GLONASS already reached the full operational capability, but due to financial problems, in 2001 the number of active satellites decreased to 7. GLONASS is Russian positioning system similar to the Global Positioning System (GPS). Nominal constellation of GLONASS consists of 24 satellites in three orbits. Each satellite broadcasts its signal on a different frequency. Two or more satellite systems are commonly named the Global Navigation Satellite System (GNSS).

The International GNSS Service (IGS) has been analyzing GLONASS observations since 2003. Nowadays, as much as 55 GNSS satellites are routinely processed by IGS and their precise 
positions are available to users through IGS products (IGS, 2013). Since GPS week 1632 (April 17, 2011), a new IGS08 terrestrial reference frame (Rebischung et al., 2012) together with an improved antenna model has been used by IGS ACs for generation of the products (orbits, Earth orientation parameters, station coordinates). The new antenna model (igs08.atx), was created by IGS to ensure consistency with IGS08 reference frame. The new model superseded igs05.atx model, which was used by IGS since 2006. Introduction of the new model allows to update phase center correction (PCC) values for existing receiver antennas to a more accurate ones, e.g., based on a greater number of calibrations and tested antennas, and with real absolute calibrations (Schmid, 2011). For the first time, the igs08.atx antenna model contains, in addition to GPS, also GLONASS specific PCCs for many receiver antennas. Before introduction of the new model, IGS recommended to use GPS specific PCCs for GPS and for GLONASS observations (this is still true for antennas which do not have estimated GLONASS PCCs).

In this paper I evaluate the effect of using GLONASS observations with GLONASS specific PCCs on coordinates and zenith tropospheric delay in GNSS regional network. Dach et al. (2010) compared 6.5-year coordinates in a global network computed with GLONASS specific PCCs with those computed with GPS specific PCCs for both systems. The maximum difference for up component reached $1 \mathrm{~mm}$. Such a small value (in comparison with differences between GPS and GLONASS specific PCC) was attributed to much smaller GLONASS constellation during analyzed period (maximally 16 GLONASS satellites, i.e., half of GPS constellation), to low ambiguity rate for GLONASS satellites, and to estimating the so called inter-system biases as constant values (other studies showed that inter-system biases significantly deviate from a constant, e.g., Schaer et al., 2009).

I computed and compared three types of solutions in which: (1) only GPS observations were used, (2) GPS and GLONASS observations were used with applying GPS specific PCCs for both systems, and (3) GPS and GLONASS observations were used with applying GPS specific PCCs for GPS observations and GLONASS specific PCCs for GLONASS observations. I used Bernese GPS Software version 5.0 (Dach et al, 2007) for processing of GNSS data collected at stations belonging to the EUREF Permanent Network (EPN) and IGS. Because Bernese ver. 5.0 does not allow to use GLONASS specific PCCs for GLONASS observations, I modified source codes of the original software to make this option possible.

\section{RECEIVER ANTENNA PHASE CENTER CORRECTIONS}

A receiver antenna PCC is usually expressed by two parameters: a phase center offset (PCO), and a phase center variation (PCV). The PCO is a mean position of the antenna's electric center relative to the antenna's reference point. PCVs, which depend on azimuth and elevation of a satellite, describe the changes that the phase center undergoes about PCO. In IGS, antenna models for receivers and satellites are provided in the ANTEX format (Rotchaher and Schmid, 2012). In an ANTEX file, PCOs and PCVs for receiver antennas are given separately for each frequency (L1, L2) and the system (GPS, GLONASS); PCVs are provided in grids.

The main observable used in GNSS analysis is ionosphere free linear combination of L1 and L2 observations: $L_{3}=\alpha_{3,1} L_{1}+\alpha_{3,2} L_{2}$. Coefficients $\alpha_{3,1}$ and $\alpha_{3,2}$ can be computed as: $\alpha_{3,1}=\left(f_{1}^{2}-f_{2}^{2}\right) / f_{1}^{2}$ and $\alpha_{3,2}=-\left(f_{1}^{2}-f_{2}^{2}\right) / f_{2}^{2}$, where $f_{1}$ denotes the $L_{1}$ frequency and $f_{2}$ the $L_{2}$ frequency of the considered satellite system. Although each GLONASS satellite broadcasts its signal on different frequency (characterized by the channel number $k$ ), coefficients for ionosphere free (or widelane) linear combination are the same for each satellite. This is because the ratio 

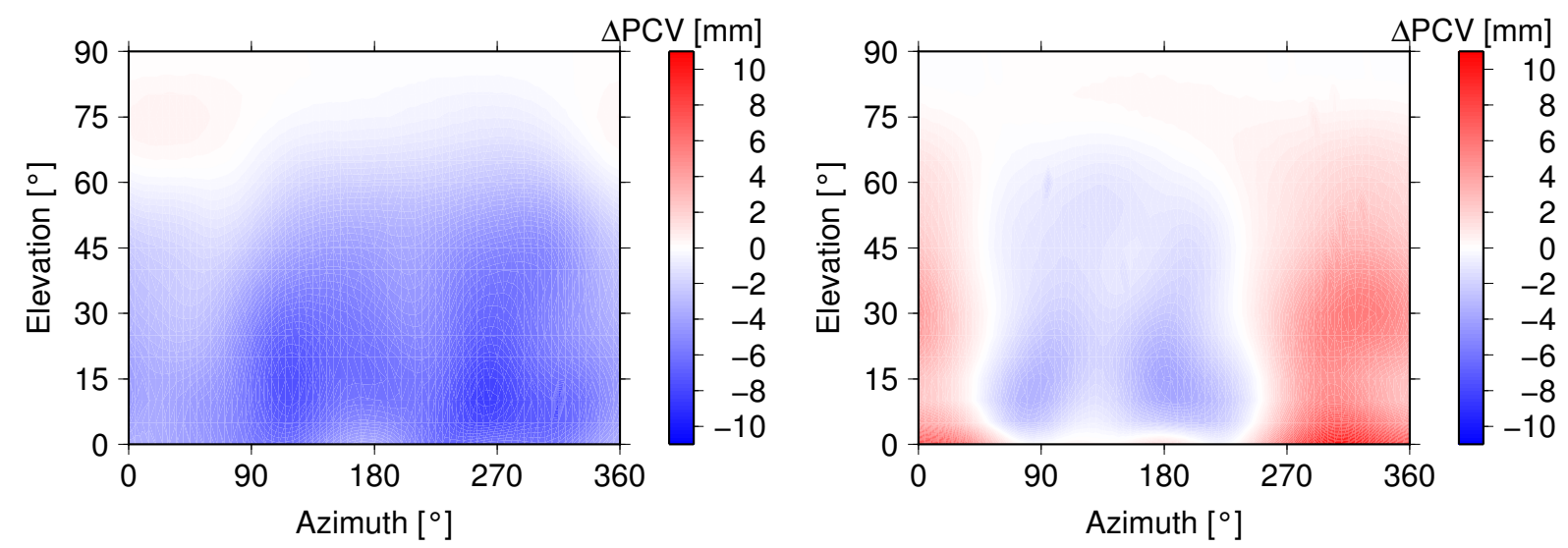

Fig. 1: Examples of PCV differences $(\triangle \mathrm{PCV})$ between GPS specific values and GLONASS specific values (for $k=0$ ). Differences are shown for L3 linear combination. On the left $\triangle \mathrm{PCV}$ for Leica antenna LEIAR25_LEIT, on the right for Novatel antenna NOV702GG_NONE

$f_{L 1, k} / f_{L 2, k}$ is constant and equal:

$$
\frac{f_{L 1, k}}{f_{L 2, k}}=\frac{9}{7},
$$

where, $f_{L 1, k}$ and $f_{L 2, k}$ are frequencies for L1 and L2 and $k$ is a channel number. GLONASS frequencies are defined according to following formulas:

$$
f_{L 1, k}=f_{0,1}+k \Delta f_{L 1},
$$

where $f_{0,1}=1.602 \mathrm{MHz}, \Delta f_{L 1}=\frac{9}{16}=0.5625 \mathrm{MHz}$, and:

$$
f_{L 2, k}=f_{0,2}+k \Delta f_{L 2},
$$

where $f_{0,2}=1.246 \mathrm{MHz}, \Delta f_{L 1}=\frac{7}{16}=0.4375 \mathrm{MHz}$. Therefore the coefficients for GLONASS are equal $\alpha_{3,1}=2.53125$ and $\alpha_{3,2}=-1.53125$. (For GPS they are: $\alpha_{3,1}=2.54573$ and $\left.\alpha_{3,2}=-1.54573.\right)$

Difference between GPS and GLONASS specific PCVs for L3 linear combination may reach $10 \mathrm{~mm}$. As an example, these differences for two antennas are depicted in Fig. 1. According to Dach et al. (2010), the mean difference between GPS and GLONASS specific PCVs corresponds to a time bias between GPS and GLONASS measurements.

GLONASS PCCs are known to be frequency dependent. In IGS ANTEX files they are given only for the channel number $k=0$ and for all GNSS receiver antennas they are provided by Geo++ GmbH. Geo++ at first computes the so-called Delta PCVs, which multiplied by the frequency difference between GLONASS and GPS, and added to GPS PCVs may be used to obtain GLONASS PCVs for any channel number $k$ (Wübbena et al., 2006).

\section{DATA ANALYSIS}

I analyzed GNSS data collected between April 17, 2011 (GPS week 1632) and December 17, 2011 (GPS week 1666) at 57 IGS/EPN stations (Figure 2) using Bernese GPS Software ver. 5.0 (Dach et al., 2007). Daily GNSS observations were processed according to three variants: 


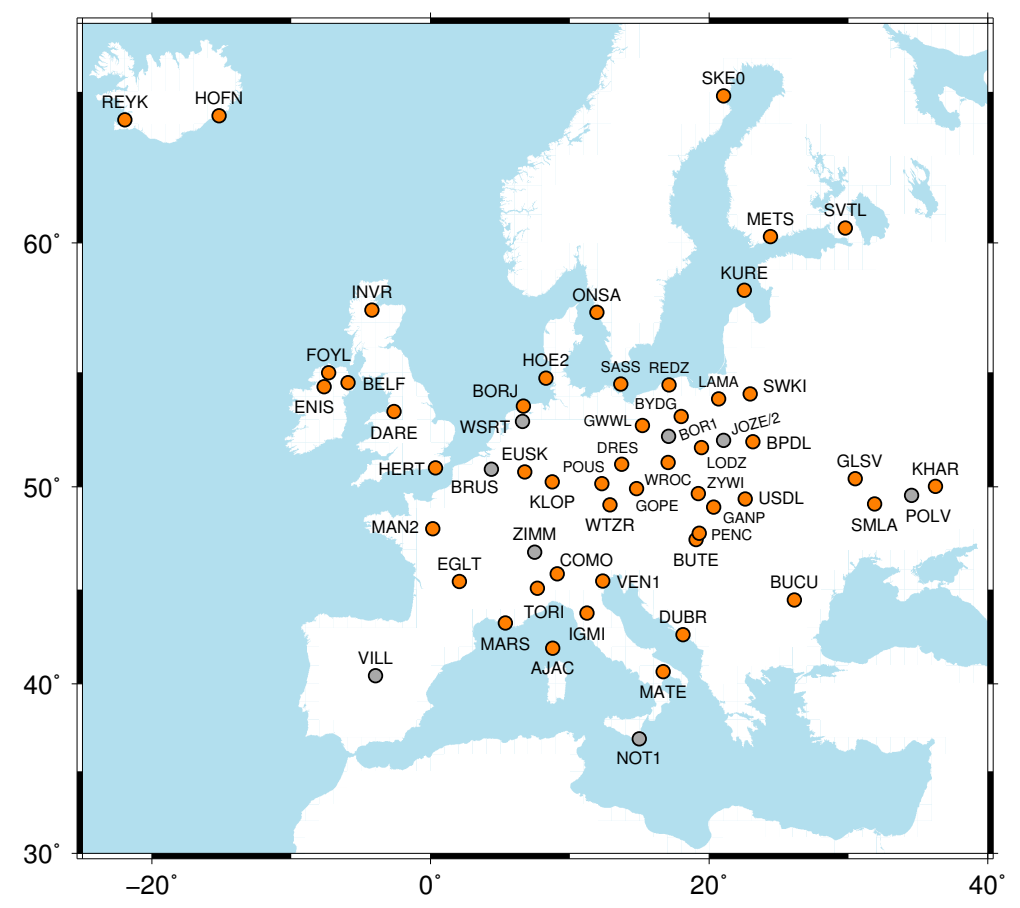

Fig. 2: Network of 57 IGS/EPN stations used in this work. Orange circles denote GPS/GLONASS observing sites; grey circles denote GPS-only IGS08 reference sites

1. GPS: only GPS observations were used in processing

2. GNSS: GPS and GLONASS observations were processed with GPS specific PCC values used for both systems

3. GNSSPCV: GPS and GLONASS observations were processed; GPS PCV corrections were used to correct GPS observations, and GLONASS specific PCV values were used to correct GLONASS observations

During analysis, the original IGS ANTEX file for GPS week 1668 (igs08_1668.atx) was used. IGS ANTEX files contain only the so-called type receiver antenna calibrations, i.e., they do not contain individual calibrations which are used, e.g., in the EPN for some stations (EPN, 2013). The characteristics of used antennas is presented in Table 1. For 47 of 49 GPS-GLONASS analyzed stations, receiver antennas had both GPS and GLONASS calibrations.

Original Bernese software ver. 5.0 does not allow to use GLONASS specific PCV corrections for GLONASS observations and GPS PCVs are used instead. To allow using GLONASS specific PCVs for GLONASS observations, I modified source codes of 3 programs (PHCCNV, MAUPRP, GPSEST) and of 2 subroutines of the Bernese package. Program PHCCNV rewrites an ANTEX file to Bernese's internal format. Antennas, that have GPS and GLONASS PCVs, were split in internal format into two antennas with slightly different names. During execution of main programs (MAUPRP, GPSEST) the station antenna name was adjusted according to GNSS system of currently processed observation, so that proper PCV values were read and used as correction to the observation. (In Bernese software, PCO is added to the regularized position of a station and PCV, which depends on azimuth and elevation of a satellite, is added 
to every observation.) Another thing that needed modification was to compute L3 GLONASS PCV corrections for receiver antennas using GLONASS frequencies. It was mentioned that GLONASS PCCs are frequency dependent. For current GLONASS constellation, channel numbers $k$ are between $<-7, \ldots, 6>$. To evaluate the maximum change of GLONASS PCVs with a frequency for antennas used in this work (Table 1), I computed differences between interpolated PCVs for the channel number $k=-7$ and those included in the ANTEX file $(k=0)$. On average, the differences were 6.5 times smaller than differences between GPS and GLONASS PCVs (compare Fig. 1) and only for 2 antennas they exceeded $1 \mathrm{~mm}$ (for several grid points of 1387). Because these differences are small comparing to GPS PCVs, and to simplify required Bernese's source code modification, I used constant GLONASS PCVs (for channel $k=0$ ) for all GLONASS frequency channels.

During processing of GNSS observations, satellite orbits and clocks were used from Center for Orbit Determination in Europe (CODE). CODE GPS and GLONASS satellite positions were given in IGS08 reference frame at epochs expressed in GPS time, and satellite clock corrections were available only for GPS satellites.

Receiver clock corrections were computed using GPS code measurements. Then the single differences were created between two points yielding the independent set of baselines separately for each daily session. I used the same baseline set in all three variants listed above; the reference baseline set was created on the basis of GNSS variant. The baselines were created using the algorithm that maximizes the number of common single difference observations over all baselines in the network. Ambiguities were resolved only for GPS satellites. I used three strategies depending on a baseline length. For GLONASS satellites ambiguity resolution is much more complicated (different frequencies) and is not supported by Bernese ver. 5.0. Thus, phase ambiguities for GLONASS satellites were estimated as real numbers. The integer nature of GLONASS double-difference ambiguities is destroyed by the so called single-difference bias (Habrich, 1999) and inter-frequency biases. Common processing of GLONASS and GPS phase observations requires also estimation of the inter-system bias. A constant part of the intersystem bias and inter-frequency biases are absorbed by real-valued ambiguities (Meindl, 2011).

After fixing ambiguities, the network solution was computed; previously fixed ambiguities were introduced and unresolved ones were eliminated from the observation system. In the network solution also tropospheric parameters were solved for, i.e., zenith delays and horizontal gradients; zenith tropospheric delays were estimated in one-hour intervals for each station. The reference frame in daily network solutions was realized by imposing the no-net-translation (NNT) minimum constraint conditions on the coordinates of eight GPS-only stations. Coordinates of these reference stations (extrapolated to the mean date of the observation session) were taken from the IGS08 reference frame (Rebischung et al., 2012).

\section{RESULTS}

\section{Coordinate comparison}

In this section I analyze the repeatabilities and the differences of coordinates computed according to three variants introduced in Data analysis section. Daily positions were detrended and residuals were transformed to the local system of each station. The following differences of analyzed solutions were computed and compared: (a) difference between GNSS and GPS, (b) difference between GNSSPCV and GPS, and (c) difference between GNSSPCV and GNSS.

The root mean squares (RMSs) of the coordinate time series were computed separately for 
Table 1: Characteristics of antenna models used in this work

\begin{tabular}{|c|c|c|c|c|c|c|c|}
\hline \multirow[t]{2}{*}{ Antenna model } & \multirow[t]{2}{*}{ Stations } & \multirow[t]{2}{*}{$\mathrm{PCV}^{a}$} & \multicolumn{2}{|c|}{$\Delta \mathrm{PCV}^{b}$} & \multicolumn{2}{|c|}{ \#antenna(\#calib.) } & \multirow{2}{*}{$\begin{array}{l}\text { Calib. } \\
\text { type }^{c}\end{array}$} \\
\hline & & & $\begin{array}{l}\text { RMS } \\
(\mathrm{mm})\end{array}$ & $\begin{array}{r}\text { Bias } \\
(\mathrm{mm})\end{array}$ & GPS & GLONASS & \\
\hline $\mathrm{AOAD} / \mathrm{MB} \quad \mathrm{OSOD}^{d}$ & ONSA & G & - & - & & & $\mathrm{Con}^{e}$ \\
\hline AOAD/M_T NONE & BOR1 VILL WSRT & G & - & - & $2(62)$ & & Rob \\
\hline ASH701945B_M NONE & BRUS & G & - & - & & & $\mathrm{Cop}^{f}$ \\
\hline ASH701945C_M OSOD & SKE0 & G & - & - & $1(2)$ & & Rob \\
\hline LEIAR25 LEIT & DARE INVR & $\mathrm{R}$ & 2.5 & -3.1 & $5(10)$ & $5(10)$ & Rob \\
\hline LEIAR25. R3 LEIT & $\begin{array}{l}\text { BORJ DRES HOE2 } \\
\text { WTZR }\end{array}$ & $\mathrm{R}$ & 1.5 & -0.3 & $5(10)$ & $5(10)$ & Rob \\
\hline LEIAR25.R3 NONE & TORI & $\mathrm{R}$ & 1.7 & -1.0 & $5(10)$ & $5(10)$ & Rob \\
\hline LEIAT504GG LEIS & $\begin{array}{l}\text { BELF BUCU EGLT } \\
\text { ENIS EUSK FOYL } \\
\text { KURE LAMA MARS } \\
\text { PENC WROC }\end{array}$ & $\mathrm{R}$ & 0.8 & -0.6 & $78(156)$ & $21(41)$ & Rob \\
\hline LEIAT504GG NONE & $\begin{array}{l}\text { AJAC HERT JOZ2 } \\
\text { MAN2 MATE VEN1 }\end{array}$ & $\mathrm{R}$ & 0.7 & -0.4 & $25(49)$ & $21(41)$ & Rob \\
\hline NOV702GG NONE & GLSV KHAR SMLA & $\mathrm{R}$ & 2.3 & 0.6 & $2(4)$ & $2(4)$ & Rob \\
\hline TPSCR3_GGD CONE & $\begin{array}{l}\text { COMO HOFN POUS } \\
\text { SASS }\end{array}$ & $\mathrm{R}$ & 0.8 & 0.9 & $159(385)$ & $47(94)$ & Rob \\
\hline TPSCR.G3 TPSH & $\begin{array}{l}\text { GOPE IGMI REYK } \\
\text { SVTL }\end{array}$ & $\mathrm{R}$ & 1.2 & 0.9 & $60(120)$ & $58(113)$ & Rob \\
\hline TRM14532.00 NONE & JOZE & $\mathrm{G}$ & - & - & & & Rob \\
\hline TRM29659.00 NONE & NOT1 POLV ZIMM & $\mathrm{R}^{h}$ & & & & & Rob \\
\hline TRM55971.00 NONE & DUBR GANP & $\mathrm{R}$ & 0.9 & 1.3 & $58(116)$ & $58(116)$ & Rob \\
\hline TRM55971.00 TZGD & $\begin{array}{l}\text { BPDL BUTE BYDG } \\
\text { GWWL KLOP LODZ } \\
\text { REDZ SWKI USDL } \\
\text { ZYWI }\end{array}$ & $\mathrm{R}$ & 1.0 & 1.0 & $8(16)$ & $8(20)$ & Rob \\
\hline
\end{tabular}

${ }^{a}$ PCV as available in igs08.atx model: $\mathrm{G}$ - PCV corrections available for GPS only; R - PCV corrections available for GPS and GLONASS

${ }^{b}$ Bias and RMS of PCV differences between GPS and GLONASS

${ }^{c}$ Rob - absolute robot calibration, Con - Relative PCC values converted to absolute values, Cop - PCC values copied from other antenna

${ }^{d} \mathrm{PCC}$ values taken from antenna AOAD/M_B with radome NONE

${ }^{e}$ Relative $\mathrm{PCC}$ values of AOAD/M_B NONE converted to absolute values

${ }^{f} \mathrm{PCC}$ values copied from AOAD/M_T_NONE antenna

${ }^{g} \mathrm{PCC}$ values taken from antenna ASH701945C_M with radome NONE

${ }^{h}$ Antenna used at GPS-only sites 
north, east and up component. In Figure 3 I present RMSs of time series of each GNSS station for the solution GPS plotted against RMSs of the solution GNSSPCV. We can notice an overall reduction of RMS for up component; on average the RMSs were smaller by $6.8 \%$ for GNSSPCV than for GPS solution; the decrease of RMS occurred for 42 of 47 (89\%) of analyzed stations. The RMSs for solutions GNSS and GNSSPCV were very similar (results not presented here): introducing GLONASS specific PCVs had no effect on repeatability of station coordinates.

Figure 4 shows an example of differences of coordinates (for three types of differences mentioned above) for two stations: DARE (Daresbury, United Kingdom) and REYK (Reykjavik, Iceland). For DARE, one can notice the significant offset in up component which equals $\sim 4 \mathrm{~mm}$ (Fig. 4c and Fig. 5a). For REYK, we could observe strong periodic signal in north component (Fig. 4 d,e). Differences between GNSSPCV and GNSS solution, for all stations, did not show any periodic signals; they were stable and with high repeatability (this could be expected since no repeatability change was noticed between these solutions), but constant offsets (biases) could be observed.

Mean differences (biases) between GNSSPCV and GNSS solutions were between $-0.5 \mathrm{~mm}$ and $1 \mathrm{~mm}$ for horizontal components, and between -2 and $4 \mathrm{~mm}$ for up component (Fig. 5a). Moreover, these biases were very similar for stations sharing the same antenna model. The exception was the behaviour of DRES station: smaller bias and more scatter results; the origin of it was not straightforward. The largest biases in up component, between 3 and $4 \mathrm{~mm}$, were observed for modern Leica antennas AR25.

Mean differences between GNSSPCV and GPS solutions, did not show any common pattern for stations with the same antenna models (Fig. 5b). On average, these differences were not smaller than the differences between GNSS and GPS solutions. Thus, GLONASS specific PCV corrections did not decrease the discrepancy between GNSS solution and GPS-only solution. Coordinate biases, at several-millimeter level, between GPS-only and GPS-GLONASS solutions were already reported by Bruyninx, (2007). Similar results were obtained by Liwosz et al., (2010) within activities of the Warsaw University of Technology EPN Local Analysis Centre. Schaer and Meindl, (2011) reported that differences between GPS-only and GPS-GLONASS results are dominated by multipath and deficiencies in the receiver antenna PCV models. To minimize the differences between GPS-only solution and GPS-GLONASS solution, they proposed to treat GPS as a reference system and to estimate for additional site-specific translation parameters
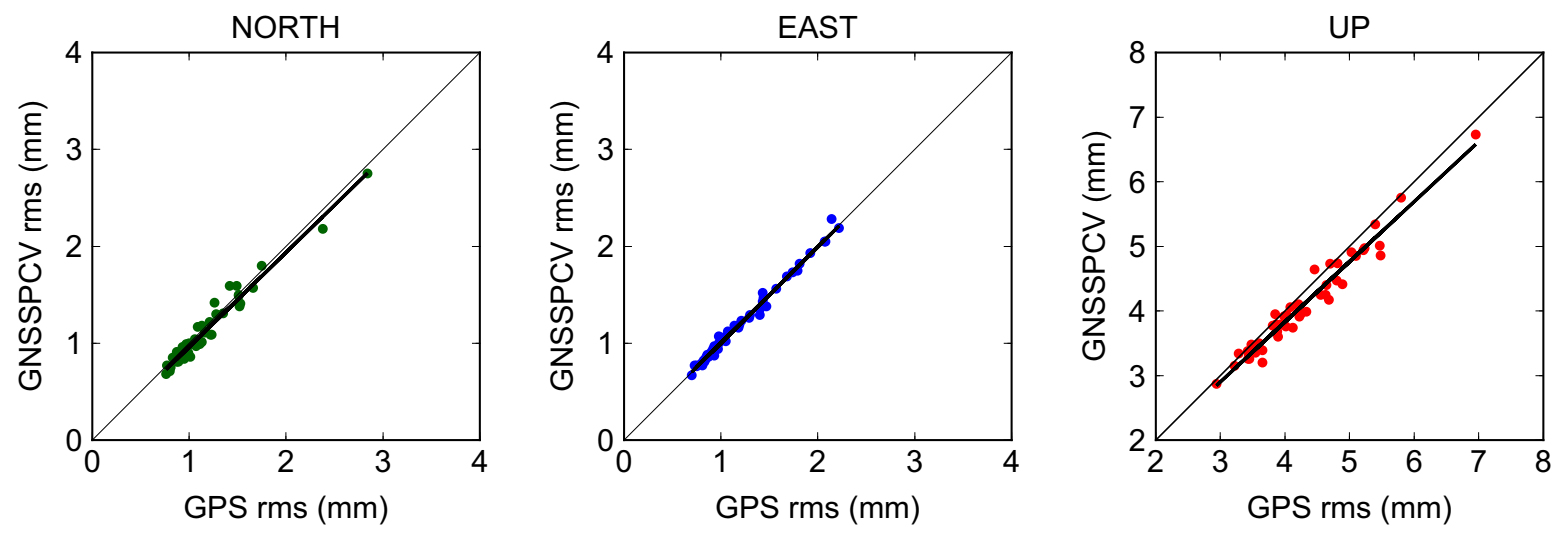

Fig. 3: Standard deviations of solution GNSSPCV with respect to GPS solution 

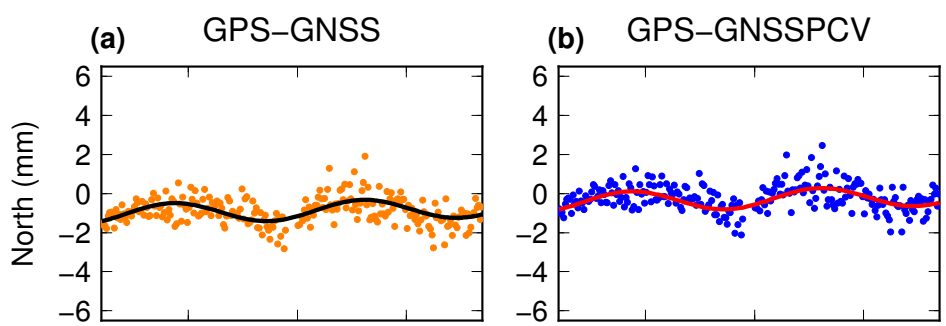

(c) GNSSPCV-GNSS
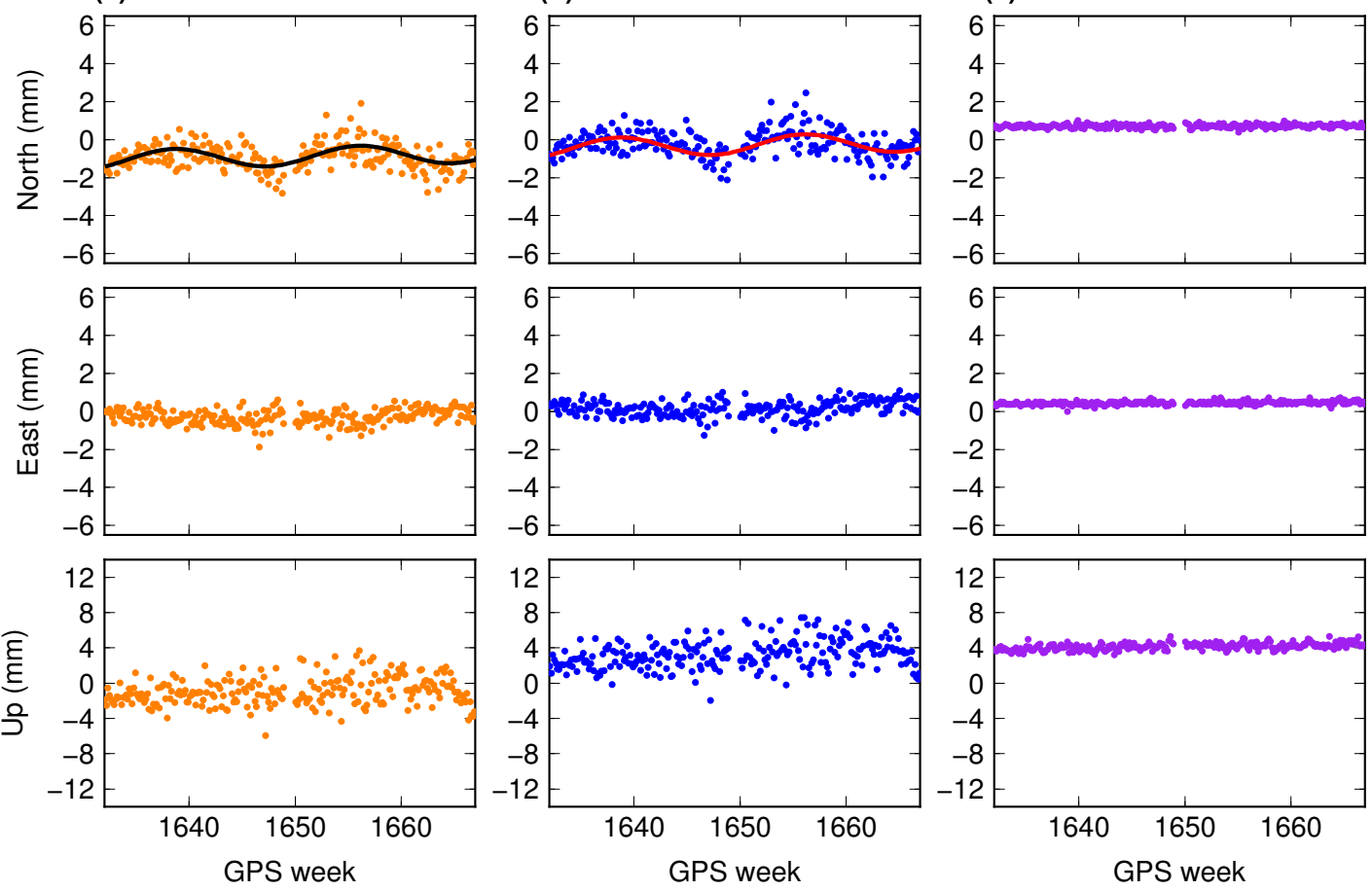

(d) GPS-GNSS
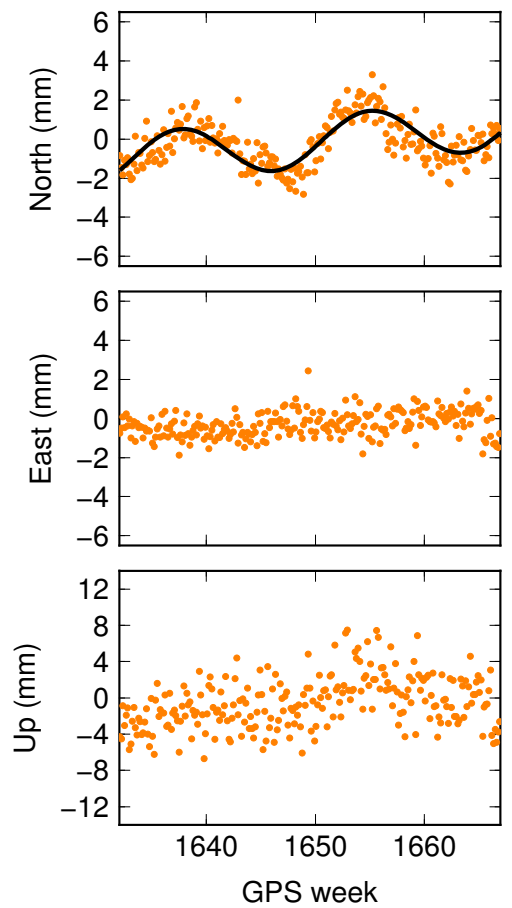

(e) GPS-GNSSPCV
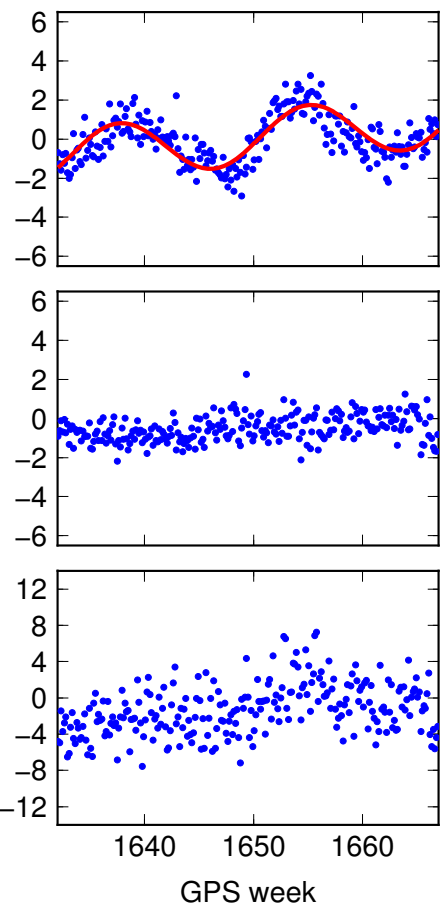

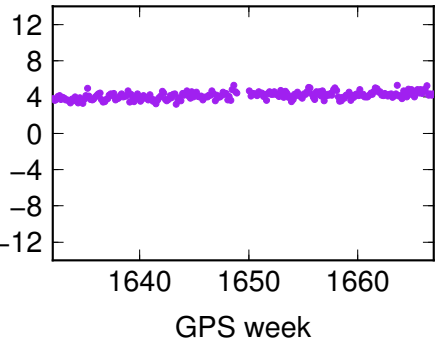

(f) GNSSPCV-GNSS
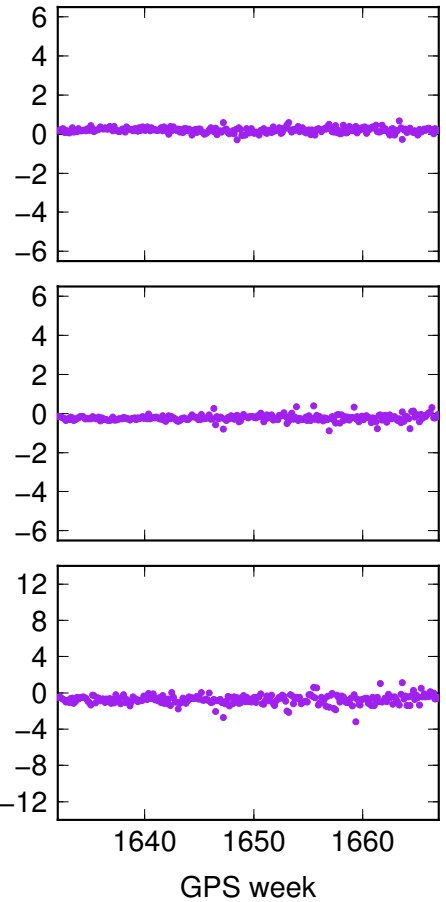

Fig. 4: Coordinate differences for DARE $(\mathrm{a}-\mathrm{c})$, and REYK (d-f). For north component in (a, $\mathrm{b}, \mathrm{d}$, e) 3 cpy signal is plotted 

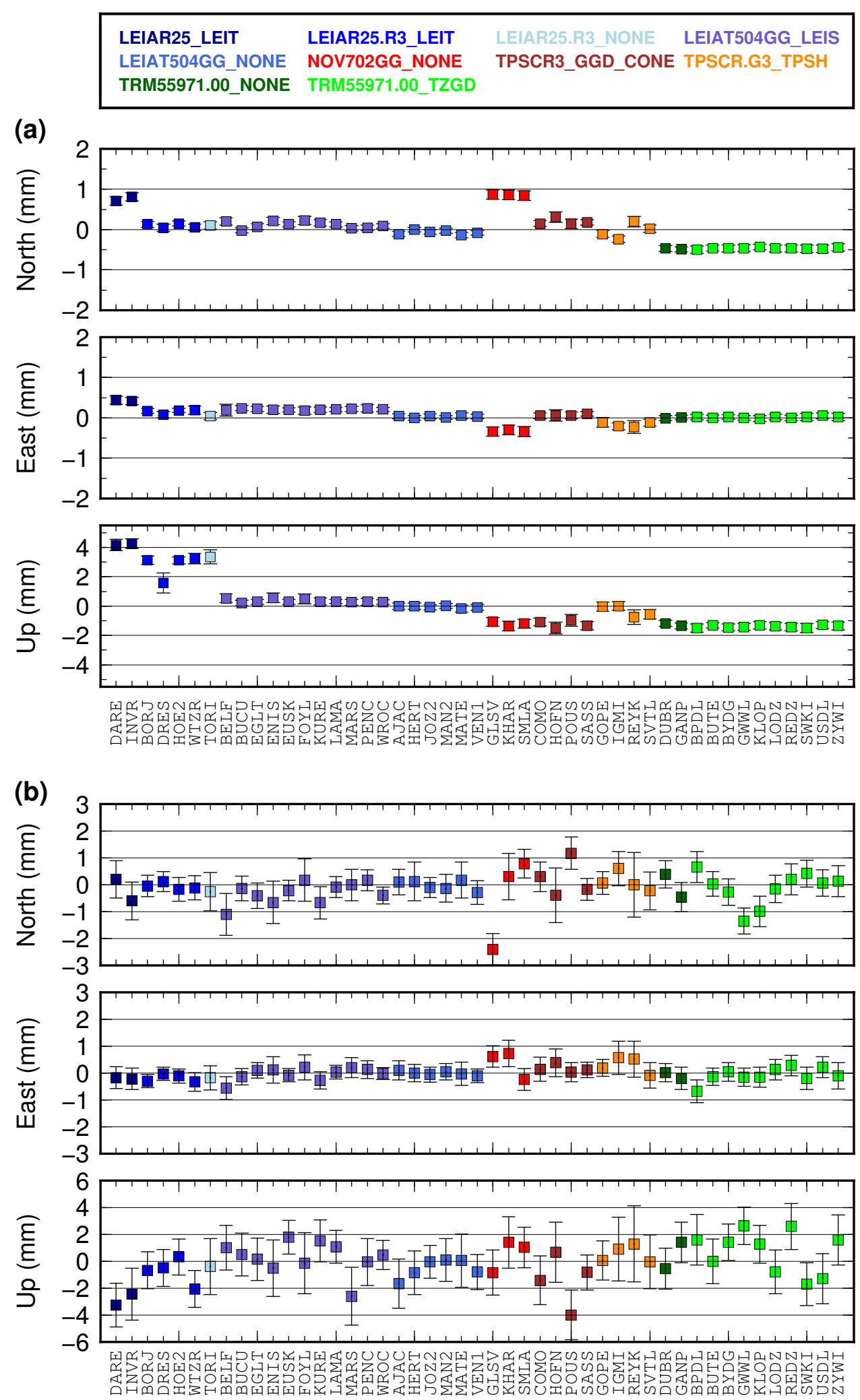

Fig. 5: Mean differences (245 days) of coordinates and their RMSs: (a) GNSS minus GNSSPCV, (b) GNSSPCV minus GPS 


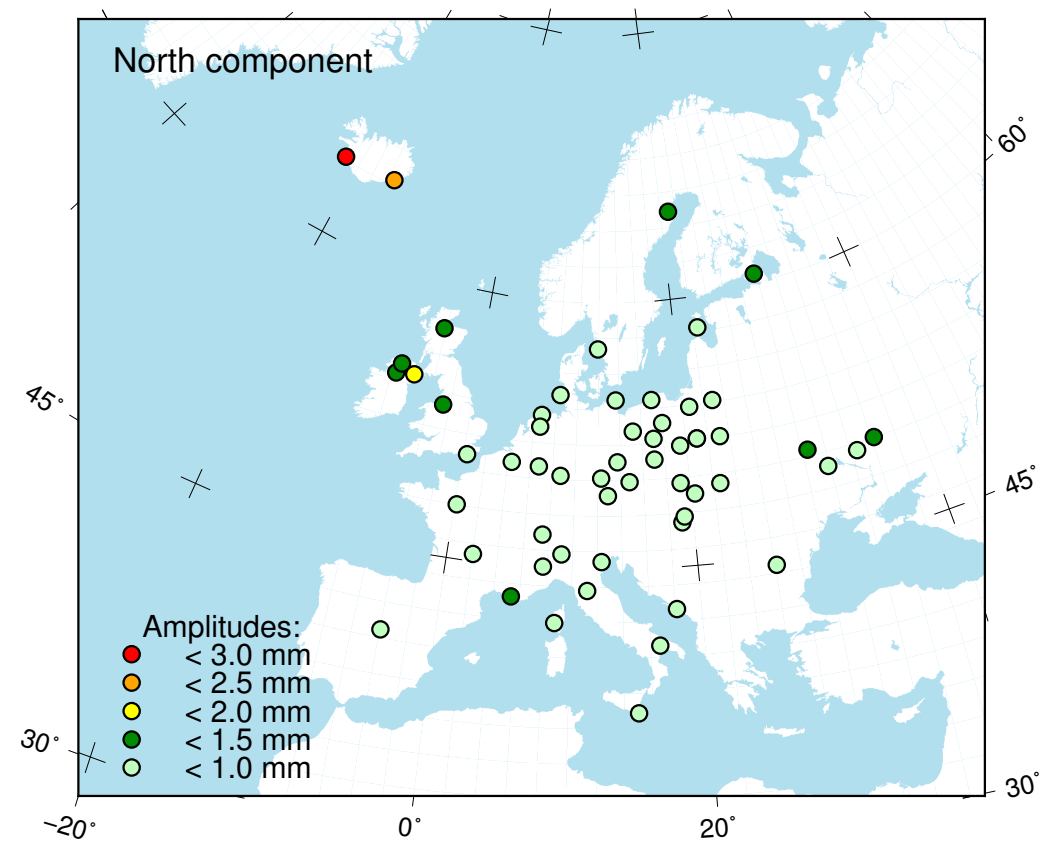

Fig. 6: Peak-to-peak amplitudes of the 120-day signal present in differential time series between GPS and GNSS solution

between GPS and GLONASS. And in future, between GPS and any other GNSS. These intersystem parameters could be set up for station coordinates and zenith tropospheric delay.

The periodic signal in north component, observed for REYK station, has a period of about 120 days $(\sim 1 / 3$ of the year) that corresponds to the frequency of about 3 cycles per year (cpy). This periodic signal was observed for other stations as well. I estimated amplitudes and phases of 1/3-year signal for GPS minus GNSSPCV time series for each station; the peak-topeak amplitudes are presented on a location map on Figure 6 . The largest amplitude could be observed for REYK $(2.8 \mathrm{~mm})$ and HOFN $(2.2 \mathrm{~mm})$ located in Iceland, and BELF $(1.6 \mathrm{~mm})$ and FOYL $(1.4 \mathrm{~mm})$ located in the United Kingdom. The presence of the 3 cpy signal in difference time series cannot tell us in which absolute time series it exists (it maybe be in both). To check this, I removed from difference time series the estimated 1/3-year signal and used these time series to reconstruct the absolute time series. For HOFN the RMS of the new time series decreased from $1.42 \mathrm{~mm}$ to $1.19 \mathrm{~mm}$ for GNSSPCV (and GNSS) solution and increased from $1.26 \mathrm{~mm}$ to 1.48 $\mathrm{mm}$ for GPS solution. For REYK the numbers were: from $1.30 \mathrm{~mm}$ to $1.19 \mathrm{~mm}$ for GNSSPCV solution and from $1.28 \mathrm{~mm}$ to $1.40 \mathrm{~mm}$ for GPS solution. For these two stations (with the largest amplitude) the results confirmed the presence of the $1 / 3$-year period, or at least larger portion of it, in GNSSPCV (and GNSS) solution. For remaining 10 stations with peak-to-peak amplitudes greater or equal to $1 \mathrm{~mm}$ (Fig. 6), the outcome of applied test suggests that for 7 stations the 1/3-year period was present in GNSSPCV (and GNSS) solution. The 3 cpy period has been found by Meindl, (2012) in GLONASS-only solution in all components expressed in geocentric system (X, Y, Z). In GPS-GLONASS solutions this period was greatly reduced and not present in GPS-only solution. He concluded that the 3 cpy period may be associated with 3 orbital planes in GLONASS. 

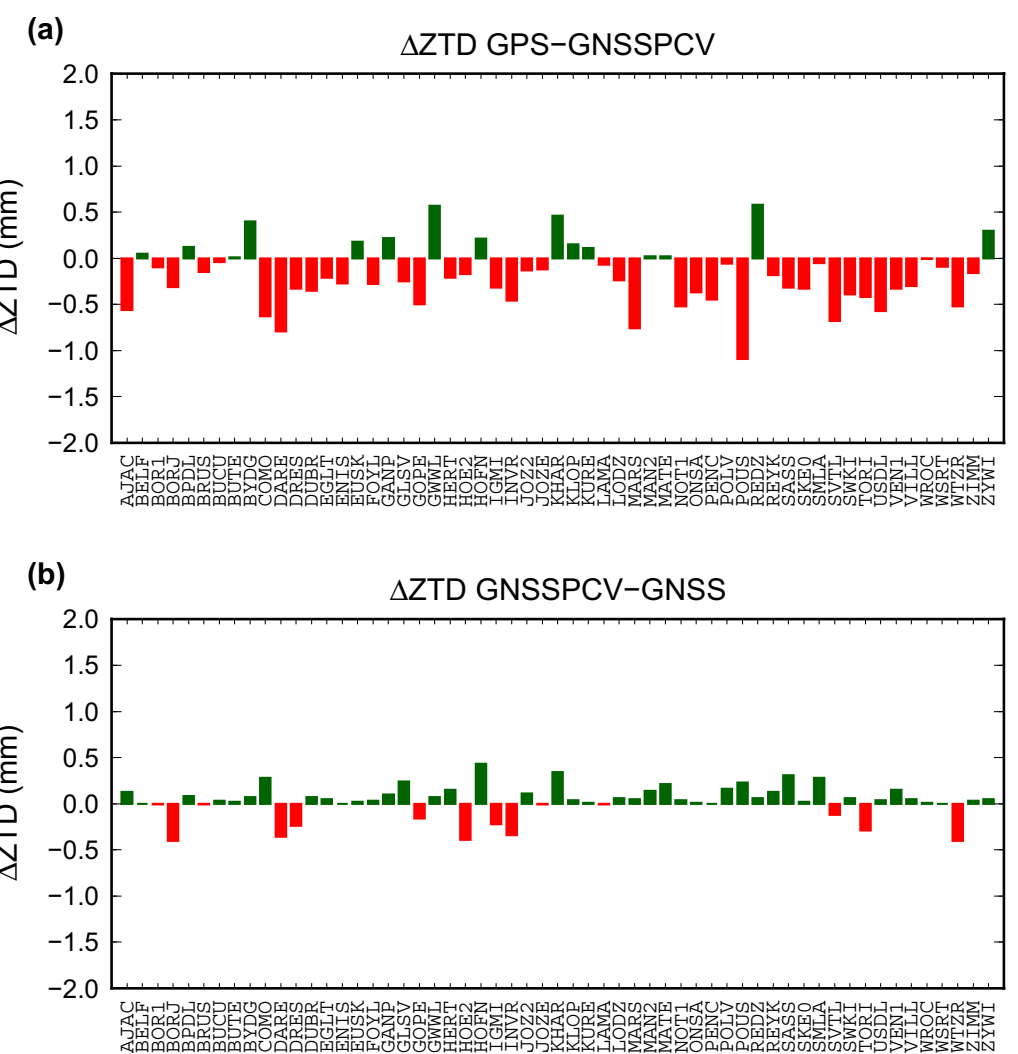

Fig. 7: Mean differences of ZTDs between analyzed solutions: (a) GPS minus GNSSPCV and (b) GNSSPCV minus GNSS

\section{Troposphere comparison}

Zenith tropospheric delay (ZTD) is estimated during processing of GNSS observations in regional or global GNSS networks. Its accuracy is the limiting factor for precise height estimation since ZTDs are highly correlated with heights.

In comparisons only mean ZTD values were used which were computed for each station from one-hour ZTD estimates. Mean differences between GPS and GNSSPCV solutions were smaller than $1.0 \mathrm{~mm}$ (Fig. 7a) with the mean bias (over 47 GNSS stations with GLONASS PCVs) equal $-0.18 \mathrm{~mm}$ (mean bias between GPS and GNSS solutions was slightly larger: $-0.20 \mathrm{~mm}$ ). Only for POUS station the difference was larger $(-1.09 \mathrm{~mm})$ and for that station also the largest height change was observed $(\sim 4 \mathrm{~mm}$, see Fig. $5 \mathrm{~b})$. Differences between solution GNSSPCV and GNSS were smaller than $0.5 \mathrm{~mm}$ (Fig. $7 \mathrm{~b}$ ).

I also compared the dependency of mean height differences and mean ZTD differences of GNSS solutions with respect to GPS-only solution (Fig. 8, results plotted for 47 GNSS stations). Slightly better linear dependency between height change and ZTD change could be observed between GPS and GNSSPCV solutions (Fig. 8b); the dependency of height change and the respective ZTD change was better recovered. This is also confirmed by the correlation coefficient which was -0.74 for GNSS minus GPS differences and -0.88 for GNSSPCV minus GPS. The difference of correlation coefficients is statistically significant $(p<0.05)$. 
(a)

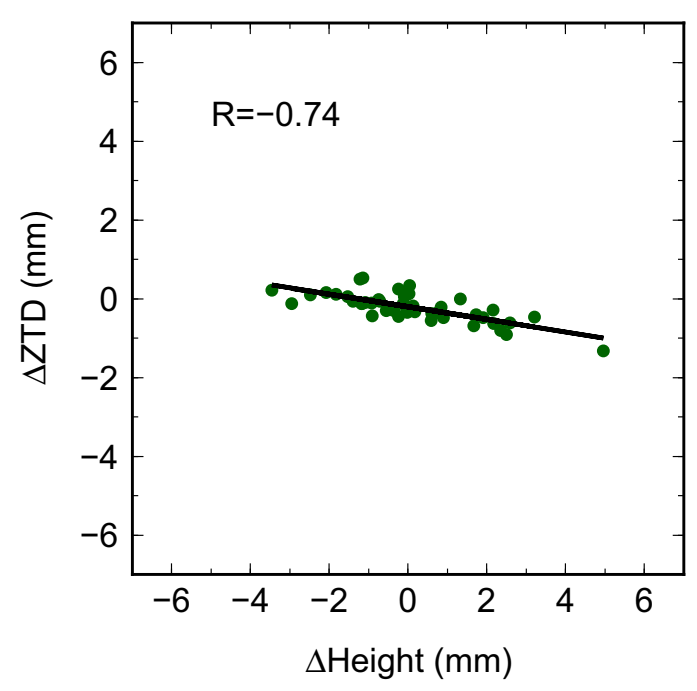

(b) GPS minus GNSSPCV

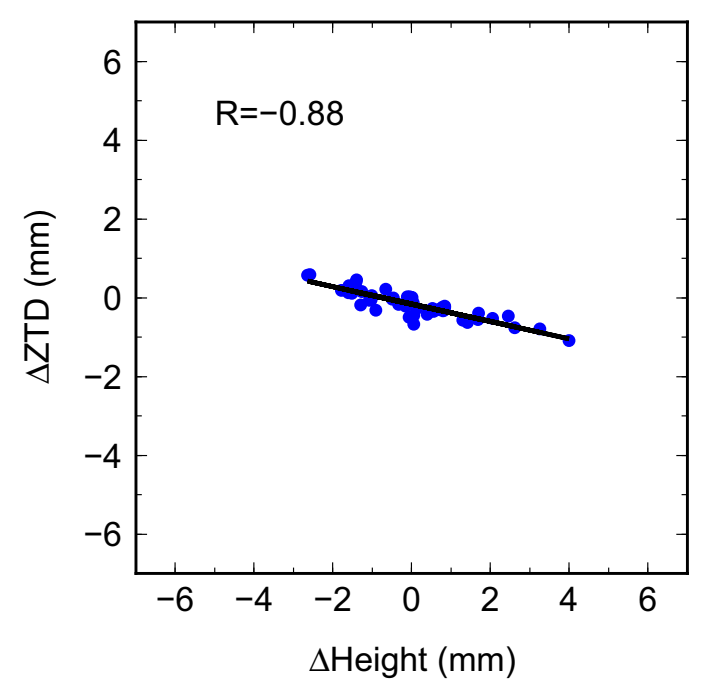

Fig. 8: Height differences wrt. zenith total delay differences. Left: GPS minus GNSS. Right: GPS minus GNSSPCV. The values of correlation coefficients $(R)$ are given on each plot

\section{CONCLUSIONS}

In this paper I have analyzed the influence of GLONASS specific PCV corrections on the results, i.e., the coordinates and zenith tropospheric delays in a regional GNSS network of selected permanent stations in Europe. The IGS, with the introduction of the new IGS08 reference frame and the associated satellite and receiver antenna models, supports GLONASS specific PCCs which can be used to correct GLONASS measurements. Before that, a common approach was to use GPS specific PCCs to correct GPS and GLONASS measurements.

Using GLONASS specific PCVs for receiver antennas in GNSS analysis affected station positions up to $1 \mathrm{~mm}$ in horizontal components, and up to $4 \mathrm{~mm}$ in up component. Observed offsets were stable over time and thus no change in repeatability of station positions was observed. Results indicate that GLONASS specific PCC are of comparable accuracy as GPS PCCs. Also, better dependency between ZTD change and the respective height change was observed for GNSS solution with GLONASS specific PCCs (with respect to GPS solution) than for GNSS solution with GPS PCCs for both systems, which indicates a more consistent observation system.

It was found, that inclusion of GLONASS observations into GPS network may produce spurious, GLONASS specific, 1/3-year period in coordinate time series of north component. The presence of this signal needs to be taken into account in analysis and interpretations of GNSS coordinate time series (e.g., spectral analysis, geophysical origins).

The impact of GLONASS receiver antenna PCVs on other parameters, e.g., phase ambiguities was not studied since Bernese GPS Software version 5.0 does not support ambiguity fixing for GLONASS observations. In December 2012, the new version, Bernese GNSS Software 5.2 was released, and it supports much more options concerning GNSS data processing, i.e., partial ambiguity fixing for GLONASS, estimation of the inter-system bias and site specific translational biases which enable to study the GNSS data processing issues in more detail. 


\section{REFERENCES}

Bruyninx, C. (2007), Comparing GPS-only with GPS+GLONASS positioning in a regional permanent GNSS network. GPS Solutions 11:97-106, DOI 10.1007/s10291-006-0041-9.

Dach, R., S. Hugentobler, P. Fridez, M. Meindl (eds.) (2007), Bernese GPS Software Version 5.0. Astronomical Institute, University of Berne.

Dach, R., R. Schmid, M. Schmitz, D. Thaller, S. Schaer, S. Lutz, P. Steigenberger, G. Wübbena, G. Beutler (2010), Improved antenna phase center models for GLONASS. GPS Solutions, 15:49-65, DOI 10.1007/s10291-010-0169-5.

EPN (2013) http://www.epncb.oma.be

Habrich, H., (1999) Geodetic Applications of the Global Navigation Satellite System (GLONASS) and GLONASS/GPS Combinations, Ph.D. thesis, Astronomical Institute, University of Bern, Switzerland.

IGS (2013) http://igs.org/components/prods.html

Liwosz, T, M. Kruczyk, J. Rogowski (2010) WUT LAC Report. 7th EPN LAC Workshop, November 18-19, 2010, Warsaw, Poland. http: //www. epncb.oma.be/_newseventslinks/ workshops/EPNLACWS_2010/day1/s2/8_wut_lac_report.pdf.

Meindl, M. (2011), Combined Analysis of Observations from Different Global Navigation Satellite Systems, University of Bern, Geodätisch-geophysikaliche Arbeiten in der Schweiz, Vol. 83.

Rebischung, P., J. Griffiths, J. Ray, R. Schmid, X. Collilieux, B. Garayt (2012) IGS08: the IGS realization of ITRF2008. GPS Solutions 16:483-494, DOI 10.1007/s10291-011-0248-2.

Rotchaher, M., R. Schmid, ANTEX: The antenna exchange Format, Version 1.4. Document available at igscb.jpl.nasa.gov/igscb/station/general/antex14.txt.

Schaer, S., , E. Brockmann, D. Ineichen (2009) Inclussion of GLONASS for EPN analysis at $C O D E /$ swisstopo Report on the Symposium of the IAG Sub-commission 1.3a Europe (EUREF) held in London, 6-9 June 2007.

Schaer, S., M. Meindl (2011) Consideration of station-specific intersystem translation parameters at CODE. Report on the Symposium of the IAG Subcommission for Europe (EUREF) held in Chisinau, Moldova, 25 - 28 May 2011

Schmid R., (2011) Upcoming switch to IGS08/igs08.atx - Details on igs08.atx. IGSMAIL 6355.

Wübbena, G., M. Schmitz, G. Boettcher, Ch. Schumann (2006), Absolute GNSS Antenna Calibration with a Robot: Repeatability of Phase Variations, Calibration of GLONASS and Determination of Carrier-to-Noise Pattern, IGS Workshop, Darmstad, Germany.

Received: 2013-08-05,

Reviewed: 2013-11-15, by Z. Siejka,

Accepted: 2013-11-21. 